\title{
Mapping the intellectual structure of GIS-T field (2008-2019): a dynamic co-word analysis
}

\author{
Seyedmohammadreza Hosseini ${ }^{1}$ (D) Hamed Baziyad ${ }^{2} \cdot$ Rasoul Norouzi $^{2} \cdot$ \\ Sheida Jabbedari Khiabani ${ }^{2} \cdot$ Győző Gidófalvi $^{3}$ (D) Amir Albadvi ${ }^{2}$. \\ Abbas Alimohammadi ${ }^{4}$. Seyedehsan Seyedabrishami ${ }^{5}$
}

Received: 1 November 2019 / Accepted: 10 December 2020 / Published online: 19 February 2021 (c) The Author(s) 2021, corrected publication 2021

\begin{abstract}
Using geographic information systems (GIS) widely for dealing with transportation problems (is well-known as GIS-T), has made it nessasary for researchers to discover the current state-of-the-art and predict the trends of future research. This paper aims to contribute to a better understanding of GIS-T research area from a longitudinal perspective, over the period 2008-2019. A co-word analysis was used to illustrate all the underlying subfields of GIS-T based on published papers in the Web of Science (WoS) database service. The main knowledge areas representing the intellectual structure of GIS-T including (a) sustainability, (b) health, (c) planning and management, and (d) methods and tools, were detected. Finally, in order to illustrate the structure and development of the identified clusters, twodimensional maps and strategic diagrams for each period were drawn. This study is the first attempt to employ a text mining method so as to detect the conceptual structure of GIS-T research area from a complex and interdisciplinary literature.
\end{abstract}

Keywords GIS-T · Text mining · Dynamic co-word analysis · Co-occurrence network · Community detection $\cdot$ Research trends

\section{Introduction}

Managing spatial information has become an interesting research topic, as a result of the development of smart city concept and its applications (Wang et al. 2019). Transportation research requires a wide range of models and analyses, and nearly always the used data have spatial reference (Goodchild 2000). Employing geographic information system (GIS) is widely regarded as a great way of dealing with transportation problems. In addition, GIS plays a crucial role in addressing the growing need for obtaining adequate data for transportation models. A GIS can be defined as a computer-based system to capture, storage, retrieval, analysis, and display of a portion of the Earth's surface (Lewis 1990). A GIS toolkit not only plays as a database system with specific functions for handling spatial

Seyedmohammadreza Hosseini reza1989@yorku.ca

Extended author information available on the last page of the article 
reference data, but also it has a set of operations for the manipulation of spatial data. Due to the capabilities of GIS to deal with spatial data, it is wildely used in a broad range of applications, from urban and regional planning to environmental management, traffic and transportation engineering, and other purposes.

Relying on the sophisticated database management system (DBMS), GIS has the ability to handle immense and diverse sets of spatially referenced data in transportation applications. Moreover, topology operations in a GIS make transportation experts enable to understand how elements contained in the database are related to each other spatially (Simkowitz 1988). Regarding the specific requirements of transportation applications, research has been directed toward enhancing the current GIS approaches to gain their full potential benefits and capabilities (Thill 2000). Over the last few years, the active application of GIS in transportation research, planning, and management has become ubiquitous increasingly, so that it is now regularly referred to by the acronym GIS-T (Waters 1999). The GIS-T can be defind as the application of information technology and related knowledge to transportation problem (Miller and Shaw 2001). In another definition suggested by Fletcher (2000), GIS-T are interconnected systems of hardware, software, data, people, and organizations for collecting, storing, analyzing, and disseminating spatial information that are used for, or influenced by transportation activities.

While GIS-T dates back to the very earliest interest in GIS in the 1960s (Goodchild 2000), the first widespread use of GIS in transportation traces back to late 1980s (Thill 2000). Three stages of development of GIS from a tool, to a technology, and finally to a legitimate domain of scientific inquiry has leaded the GIS-T into a stage of maturity (Goodchild 1992). Meanwhile, transportation has evolved from its origins in pure spatial sciences to the multidisciplinary and multi-faceted reality of transportation infrastructure and flows of passengers and freight (Thill 2000). Goodchild (2000) characterizes the evolution of GIS-T in three steps: (a) map view, which favors GIS-T applications linked to data inventory, data accuracy and interoperability; (b) navigational view, which mostly concentrates on the storage of time-dependent attributes and also miscellaneous representations related to map scales; (c) behavioral view, which derives from Hägerstrand's time geography, treating transportation events as dynamic and occurring within the largely static transportation space. All in all, a review of the past GIS-T advances implies that progress has been made in the areas of using GIS-T as spatial databases, analysis and modeling tools, and communication tools (Shaw 2010).

The existing literature in a field commonly provides a good scientific research base for researchers to develop new frameworks and hypotheses (Hoz-Correa et al. 2018). Co-word analysis enables us to illustrate an overall picture of contents on a specific domain through counting and analyzing the co-occurrences of words in bibliographical units such as journal and conference papers, research reports, book chapters, and the like (Liu et al. 2011). Co-word analysis is a quantitative method to map the relationships and interrelationships among concepts, ideas, and problems in different scientific fields (Zhang et al. 2017). Coword analysis is widely used in bibliometric and scientometric studies, whose theoretical roots go back to actor-network theory (Yang et al. 2012; Igami et al. 2014; Nguyen 2019). Many researchers have used the co-word analysis to explore conceptual network in different subjects and disciplines such as Library and Information Science (Liu et al. 2011; Olmeda-Gómez et al. 2017), Medicine (Xie 2015; Hoz-Correa et al. 2018; Nguyen 2019), International Management Science (Yue 2012), Urbanization (Zhang et al. 2017), Epidemiology (Baziyad et al. 2020), Supply Chain Management (Shiau et al. 2015), Software Engineering (Coulter et al. 1998), Scientometrics (Ravikumar et al. 2015), Information Metrics (Khasseh et al. 2017), Neural Network (Noyons and van Raan 1998), Internet of 
Things (Yan et al. 2015), Social Media (Gan and Wang 2015), Open Data (Corrales-Garay et al. 2019), and Marketing (Wang et al. 2015).

To our knowledge, no research based on text mining methods has been carried out for discovering the hidden information in the field of GIS-T. Therefore, this study attempts to map the knowledge domains of GIS-T through the co-word analysis, over the years 20082019. This paper will be helpful for the researchers quickly grasping the current state-ofthe-art and providing a basis for its future direction and development. The remainder of this paper is organized as follows: In the next section, we introduce the constructing process of co-word network and essential network theories. "Results and discussion" section presents the analytical results, elaborates on the underlying discussions and proposes some valuable implications for further academic studies or policy formulation. In the last section, we summarize the major conclusions for the paper.

\section{Methodology}

The present paper applies co-word analysis to visualize all the interconnected subjects of GIS-T research field, and find out the interrelationships of keywords. The main aim of this study is to present the current status of research on GIS-T and analyze the future trends of its development from a longitudinal perspective. Diversity and variety of research topics in different scientific fields, have made it necessary for researchers to identify the areas and domains of the current research. Bibliometric term was defined by Pritchard (1969) as "the application of mathematical and statistical techniques to books and other communication means". Bibliometrics applies different quantitative analysis methods including citationbased, co-authorship and co-word analysis to explore the existing patterns in a specific field (Van Eck and Waltman 2014).

Co-word analysis was firstly introduced by Callon et al. (1983), which became an effective technique for mapping the strength of association between information sections in textual contexts (Viedma-Del-Jesús et al. 2011). This technique is based upon the assumption that a group of aggregated keywords could provide an adequate description of a papers's content, thus underlying themes in a research field can be characterized by a list of the most important keywords (Cambrosio et al. 1993; Yan et al. 2015; Khasseh et al. 2017; Hoz-Correa et al. 2018). The more overlapping pair of keywords within the analyzed papers, the higher probability of a relationship among them (Igami et al. 2014). Co-word analysis makes it possible that researchers demonstrate a comprehensive picture of a specific domain through words' co-occurrence in different types of bibliometric units such as book chapters, journal and conference papers, and books (Liu et al. 2011). In this paper, a co-word analysis method is employed for mapping the intellectual structure of "GIS-T" field through a collection of papers from Web of Science (WOS). Fig. 1 illustrates an overall picture of method employed in this study.

\section{Data collection}

To fulfill our goal in this study, the relevant publications accepted as GIS-T in academic literature were screened. The literature was retrieved on December 31, 2019 from all the existing publications on the topic included in the core database of Web of Science (WoS). Using the data extracted from Web of Science, a new dataset including all journal and conference papers from 2008 to 2019 was generated. Relying upon several highly frequent 


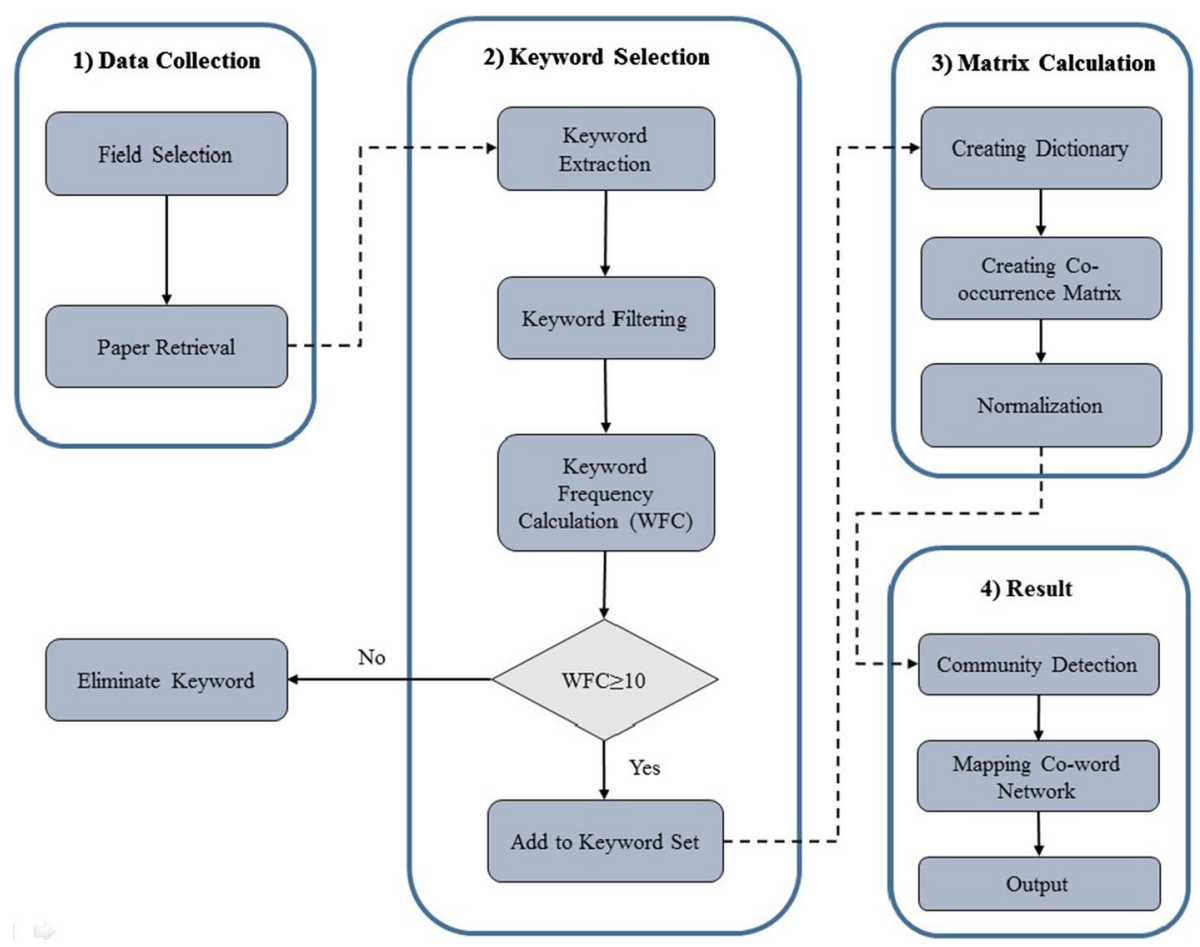

Fig. 1 A comprehensive framework for designing intellectual structure based on co-word analysis

keywords extracted from previous research works, the keyword combinations used to search were as follows: TS $=(($ "GIS" OR "geographical information system*" OR "geographic information system*" OR "geographical information science" OR "geographic information science" OR "geospatial information system*" OR "geospatial information science") AND ("transportation" OR "road network" OR "traffic accident" OR "traffic noise" OR "transit” OR “cycling” OR “walking”)).

TS field is a search based on the "Topic" including title, abstract and keywords. The structured search returned 4236 records. Afterwards, the authors eliminated the partially duplicated records in the dataset, then read the titles and abstracts of papers to leave immaterial papers out. After examining the results, we found 171 of records completely irrelevant and off-topic (such as transportation of wind, dust, animals etc.). Another part (around 80) of cleaning process was for the elimination of papers that were published in the less prestigious journals and conferences, based on the authors' knowledge. Also, we had to exclude the papers without any keywords from the analysis (219 papers). Finally, the new dataset of 3766 bibliographic records was designed. The final dataset contains the following information: publication title, author name, journal title, year published, abstract, keywords provided by publication authors and keywords indexed by Web of Science.

\section{Keyword selection}

It is assumed that the more relevant keywords chosen for the research, the better quality of the knowledge gained from the co-word network. Keyword selection helps researchers to 
study on a set of keywords that are more relevant to the topic. One of the most frequently used criteria for keyword selection in co-word analysis is frequency, which is used in this paper, too. In this paper, keywords with at least ten frequencies were applied for participation in co-word network. There are two stages prior to final keyword selection, namely keyword extraction and keyword filtering:

\section{- Keyword extraction}

Keyword extraction is the process of choosing an initial set of keywords for studying. There are two ways to extract keywords from texts, namely non-parametric and parametric. Non-parametric method retrieves keywords, titles and abstracts cited by academic publications manually. Parametric approach uses different software to extract keywords from text such as Ti.exe, GenEx etc., which employ an algorithm to select keywords illustrating main topics of a particular subject (Ravikumar et al. 2015). In this study, the non-parametric way of keywords extraction is employed.

- Keyword filtering

In keyword filtering, we try to clean and refine the extracted keywords, based on different criteria. The keywords of papers included in the dataset were filtered based on the following criteria: (a) standardization of keywords in singular and plural forms (e.g., "street", "streets"); (b) combination of acronyms (e.g., "GIS", "Geographic Information System"); (c) elimination of general keywords (e.g., "data", "information", "model", "system"); (d) combination of the British and American spelling of keywords (e.g., "optimize", "optimization"); (e) standardization of derived keywords (e.g., "access", "accessibility"). Once the keywords of publications are filtered, a sample of 1498 individual keywords remained. The findings reveal that 1498 keywords were repeated 15,145 times in 3766 papers. The combination of "transportation" keyword with other words in the contexts has led to creation of expressions such as "transportation system", "public transportation", "transportation planning" etc. Consequently, for this study, only the existing expressions of "transportation" were taken into account.

\section{Matrix calculation}

Co-word network works based on co-occurrences of keywords extracted from feature selection phase. First, a dictionary including a number of each two keywords co-occurrences is created. For instance, ("Built Environment", "Walkability", 25) explains that "Built Environment" and "Walkability" are appeared simultaneously in 25 papers. Then, the cooccurrence matrix of the dictionary is created. Various approaches have been employed for normalization of co-occurrence network, such as Pearson (Yan et al. 2015; Wu et al. 2018), Jaccard index (Peters and Van Raan 1993), Salton index (Ravikumar et al. 2015; Yue 2012), and Equivalence index (Muñoz-Leiva et al. 2012; Zong et al. 2013). Normalization of co-occurrence network is still a controversial issue (Leydesdorff and Vaughan 2006), thus researchers utilize different methods for normalizing the co-word networks. In this paper, we utilized the Jaccard index for normalization of the co-occurrence matrix.

\section{Result}

A clustering method needs to be used on normalized co-occurrence network to find different existing themes of the field. Clustering methods try to group similar and more relevant keywords into a cluster. In this paper, a community detection algorithm is employed on 
co-word networks. In addition, Modularity index was utilized to evaluate the quality of clustering result, which is missed in many co-word analysis papers. If clustering method satisfy the validation criteria, then co-word network is visualized. An appropriate visualization method could bring researchers a comprehensive overview of a field in a quick look. Various software can be used for the visualization of co-word network, such as VOSviewer (Eck and Waltman 2009), SciMAT (Cobo et al. 2012), Bibliometrix (Aria and Cuccurullo 2017), Gephi (Bastian et al. 2009) and so on. In this paper, Gephi was used, due to its flexibility and powerful visualization. Finally, based on the clustered co-word map, different types of research themes are identified and labeled according to total involved keywords of each cluster.

\section{Results and discussion}

\section{Statistical analysis}

Figure 2 shows the quantification of papers chronologically between 2008 and 2019 (3766 papers). It can be vividly seen that research into GIS-T witnessed almost a moderate rate of growth between 2008 and 2019.

Table 1 lists the journals with most papers published on GIS-T. The "Transportation Research Record" contains 119 published papers during the analyzed period. With regard to the variety of journals that have published papers on GIS-T, it can be concluded that research on this research area is multidisciplinary, from transportation to GIS, computer science etc. The journals "Journal of Transport Geography", and "International Journal of Environmental Research and Public Health" have ranked second and third accounting for 117 and 56 respectively. Moreover, according to our database, "Billie Giles-Corti" is the most prolific author with 41 papers, James F. Sallis and Suzanne Mavoa with 30 and 25 respectively (see Table 2 ).

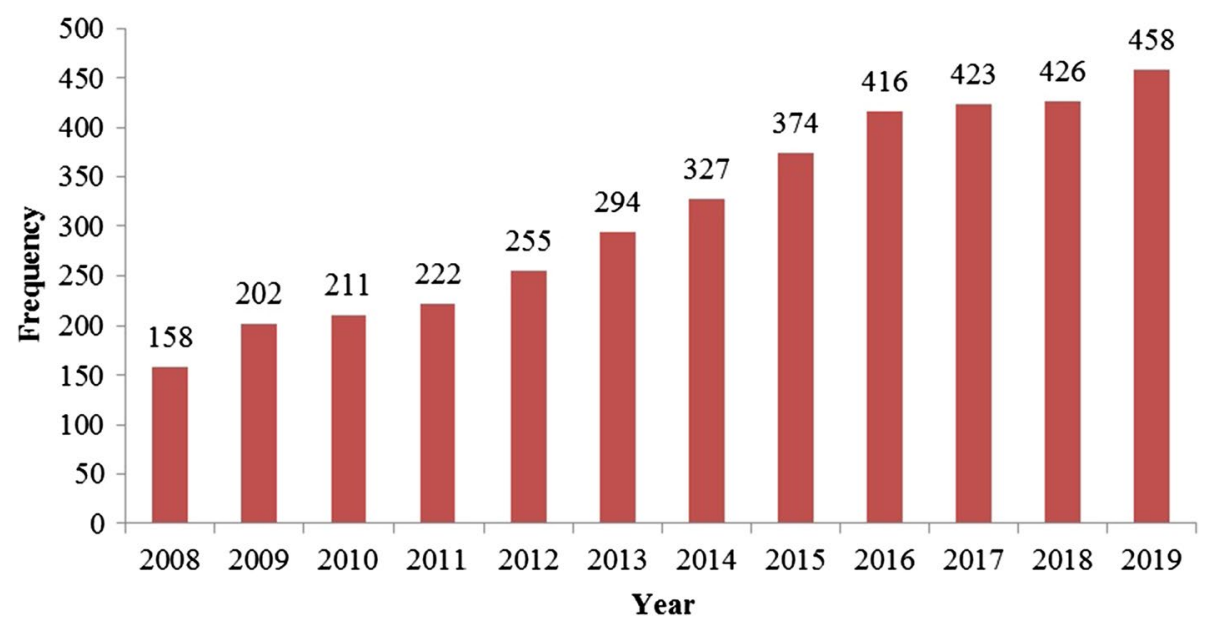

Fig. 2 Number of papers published in years from 2008 to 2019 
Table 1 Distribution of the papers among different journals

\begin{tabular}{|c|c|c|c|}
\hline Journal & JCR Rank & Frequency & $\%$ \\
\hline Transportation Research Record & Q2 & 119 & 0.031 \\
\hline Journal of Transport Geography & Q1 & 117 & 0.031 \\
\hline International Journal of Environmental Research and Public Health & Q2 & 56 & 0.015 \\
\hline Sustainability & Q3 & 54 & 0.014 \\
\hline Applied Geography & Q1 & 46 & 0.012 \\
\hline ISPRS International Journal of Geo-Information & Q1 & 44 & 0.011 \\
\hline International Journal of Health Geographics & Q2 & 44 & 0.011 \\
\hline International Journal of Behavioral Nutrition and Physical Activity & Q2 & 42 & 0.011 \\
\hline International Journal of Geographical Information Science & Q1 & 41 & 0.010 \\
\hline Transportation Research Part A: Policy and Practice & $\mathrm{Q} 2$ & 36 & 0.009 \\
\hline Transportation Research Part D: Transport and Environment & Q1 & 36 & 0.009 \\
\hline
\end{tabular}

Table 2 Top ten authors in the topic GIS-T

\begin{tabular}{lllr}
\hline Author & Knowledge areas & Frequency & $\%$ \\
\hline Billie Giles-Corti & Urban Planning / Physical Activity / Health & 41 & 0.010 \\
James F. Sallis & Physical Activity / Built Environment / Health & 30 & 0.008 \\
Suzanne Mavoa & Health / Built Environment / Spatial Analysis & 25 & 0.007 \\
Lawrence Frank & Transportation / Urban Planning / Physical Activity & 24 & 0.006 \\
Brian E. Saelens & Obesity / Physical Activity / Policy & 21 & 0.005 \\
Terry L. Conway & Physical Activity / Built Environment / Health & 20 & 0.005 \\
Neville Owen & Physical Activity / Built Environment / Public Health & 19 & 0.005 \\
Jacqueline Kerr & Physical Activity / Built Environment / Health & 17 & 0.004 \\
Biswajeet Pradhan & GIS / Geoinformatics / Geospatial Analysis & 17 & 0.004 \\
\hline
\end{tabular}

As mentioned earlier, the papers without keywords were eliminated from our analysis. Also, in our study, both author keywords and keyword plus were analyzed. Once the keywords of publications are filtered, a sample of 1498 individual keywords remained. The findings reveal that this 1498 keywords were repeated 15145 times in 3766 papers. The top ten frequently occuring keywords are "walking", "transportation", "built environment", "health", "accessibility", "physical activity", "obesity", "GPS”, "spatial analysis" and "network analysis" (see Table 3).

\section{Calculation of co-occurrence matrix and creation of thematic network}

A co-occurrence matrix was calculated based on common keywords in a paper for providing co-word network. For instance, the keywords "built environment" and "walkability" are appeared in author keywords of 25 papers simultaneously. As a result, the weight of their co-occurrence equals to 25 . After the calculation of co-occurrences matrix, a square matrix comprising 636 frequently repeated keywords was formed. The top 10 keywords with a highest degree centrality and betweenness centrality among our dataset are listed (see Table 4). The degree centrality of a node equals to total summation of direct links related to a node. The more degree centrality for a specific keyword indicates that the keyword is 
Table 3 Highly occuring keywords covered in 3766 papers

\begin{tabular}{|c|c|c|c|c|c|c|c|}
\hline No. & Keyword & $\mathrm{OCC}$ & $\%$ & No. & Keyword & $\mathrm{OCC}$ & $\%$ \\
\hline 1 & Walking & 479 & 0.031 & 13 & Simulation & 68 & 0.004 \\
\hline 2 & Transportation & 435 & 0.028 & 14 & Mobility & 65 & 0.004 \\
\hline 3 & Built environment & 327 & 0.021 & 15 & Road network & 63 & 0.004 \\
\hline 4 & Health & 297 & 0.019 & 16 & Transit & 62 & 0.004 \\
\hline 5 & Accessibility & 232 & 0.015 & 17 & Land-use & 60 & 0.003 \\
\hline 6 & Physical activity & 187 & 0.012 & 18 & Urban design & 55 & 0.003 \\
\hline 7 & Obesity & 150 & 0.009 & 19 & Logistics & 45 & 0.002 \\
\hline 8 & GPS & 110 & 0.007 & 20 & Urban planning & 43 & 0.002 \\
\hline 9 & Spatial analysis & 99 & 0.006 & 21 & Pollution & 40 & 0.002 \\
\hline 10 & Network analysis & 71 & 0.006 & 22 & Travel behaviour & 38 & 0.002 \\
\hline 11 & Urban form & 92 & 0.006 & 23 & Sustainability & 36 & 0.002 \\
\hline 12 & Network analysis & 72 & 0.004 & 24 & Public transport & 34 & 0.002 \\
\hline
\end{tabular}

$O C C$ occurence of keywords

Table 4 Top keywords with high degree centrality and betweenness centrality

\begin{tabular}{llllll}
\hline No. & Keyword & $D C$ & No. & Keyword & $B C$ \\
\hline 1 & Physical activity & 148 & 1 & Urban form & 0.031 \\
2 & Emission & 143 & 2 & Physical activity & 0.030 \\
3 & Sustainability & 139 & 3 & Walking & 0.026 \\
4 & Connectivity & 135 & 4 & Sustainability & 0.023 \\
5 & Health & 133 & 5 & GIS Data & 0.022 \\
6 & Pedestrian & 132 & 6 & ArcGIS & 0.021 \\
7 & Built environment & 129 & 7 & Network analysis & 0.020 \\
8 & Transport system & 127 & 8 & Transport system & 0.019 \\
9 & Mapping & 127 & 9 & Built environment & 0.019 \\
10 & Urban mobility & 125 & 10 & Health & 0.019 \\
\hline
\end{tabular}

$D C$ degree centrality; $B C$ betweenness centrality

used more frequently in papers. The degree centrality is employed to calculate the level of centrality in strategic diagrams. As such, the total number of degree centrality of nodes in a community, regardless of internal links, with other communities is equal to centrality in a strategic diagram. The degree centrality of a node is defined based on its direct links in the network and equals to total summation of direct links related to chosen node as shown in Eq. 1. In a co-word network, the keywords with high degree centrality represent the current main research subjects in GIS-T such as "physical activity", "emission", "sustainability", "connectivity", "health", and so on.

$$
D C(x)=\operatorname{dig}(x) \quad \operatorname{dig}(x) \text { is the degree of node } x .
$$

On the other hand, betweenness centrality is calculated based on shortest path in a network. The betweenness centrality shows that to what extent the knowledge points are able to link with other independent subjects in the field. Betweenness centrality is defined as a proportion between the total numbers of the shortest path passes from node connecting node $\mathrm{i}$ to node $\mathrm{j}$ and the total number of shortest paths existing between node $\mathrm{i}$ and node 
$\mathrm{j}$ as represented in Eq. 2. Keywords with great betweenness centrality like "urban form", "physical activity", "walking", "sustainability", "GIS data" etc., are regarded as connectors among research topics. In other words, these keywords have interdisciplinary resources and concepts, thus they are supposed to greatly affect the co-occurrence of other keywords (Zhang et al. 2017).

$$
B C(x)=\sum_{s, t \in x} \frac{\sigma_{\mathrm{st}}(x)}{\sigma_{\mathrm{st}}}
$$

Where $\sigma_{\mathrm{st}}$ is the total number of shortest paths between node $s$ and $t$ as their end nodes, while $\sigma_{\mathrm{st}}(x)$ is the total number of shortest paths that pass through node $x$. High centrality scores indicate that a vertex lies on a considerable fraction of shortest paths connecting pairs of vertices.

A network has cluster structure if it categorizes into different groups of vertices with dense connections within groups and sparser connections between groups (Xie and Szymanski 2011). In order to design a visual keyword co-occurrence network, the keywords with a minimum frequency of two were selected for the co-occurrence analysis. The quality of a particular part of network into clusters is commonly measured through modularity (Newman 2004).

$$
Q=\frac{1}{4} \sum_{i j}\left(A_{\mathrm{ij}}-\frac{k_{\mathrm{i}} k_{\mathrm{j}}}{2 m}\right) S_{\mathrm{i}} S_{\mathrm{j}}, \quad m=\frac{1}{2} \sum_{i} k_{\mathrm{i}}
$$

where $k_{\mathrm{i}}$ and $k_{\mathrm{j}}$ are the degrees of nodes and $\mathrm{m}$ is total number of edges. $A_{\mathrm{ij}}$ is the number of edges between vertex $i$ and $j$. The quantities $A_{\mathrm{ij}}$ are the elements of the so-called adjacency matrix. The expected number of edges between vertices $i$ and $j$ if edges are placed at random is $\frac{k_{\mathrm{i}} k_{\mathrm{j}}}{2 m}$. A network with modularity in the range between 0.3 and 0.7 , usually is identified a strong cluster structure (Xie and Szymanski 2011). The rate of modularity for the network in this study accounted for 0.321 . According to the standard value, this is not great, but acceptable and satisfying. One justification for achieving this value would be the interdisciplinary nature of GIS-T including transportation, GIS, computer science and so on, that leads to a stack of papers with diverse viewpoints and objectives.

Over the last years, a variety of softwares have been developed in order to visualize emerging trends and transient patterns in scientific literature such as MedlineR (Lin et al. 2004), CiteSpace (Chen 2006), Gephi and so on. Figures 3, 4, 5 and 6 illustrate thematic networks of GIS-T research for periods between 2008 and 2019, which were built up using the Gephi 0.9.2. Gephi software is able to visualize and analyze co-word network as a type of co-occurrence networks. One of the main advantages of Gephi is its capability to visualize co-occurrence networks with a more beautiful appearance. Many researchers have applied this software in co-word analysis networks (Feng et al. 2017; Li et al. 2018; Rashidi et al. 2020). In a thematic network, the weight of each topic represents its total link strength which are shown by the size of each corresponding node. The links indicate co-occurence relationships among keywords, and the distances among the nodes are inversely related to the closeness of subjets. Total link strength is defined as the sum of the number of links a node shares with all other nodes in the network. Concepts related to the same communities are presented in the same colour (see Figs. 3, 4, 5 and 6, and "Construction of strategic diagram\}" section ). Based on co-word network analysis, there will be an edge between two-keywords existing in a paper, which indicates the co-occurrence of these keywords. Apparently, it is 
Table 5 Co-word structure of the thematic maps between 2008 and 2019

\begin{tabular}{lllll}
\hline Period & Nodes & Edges & Density & $\begin{array}{l}\text { No. of } \\
\text { clus- } \\
\text { ters }\end{array}$ \\
\hline $2008-2010$ & 14 & 17 & $0.186 \%$ & 4 \\
$2008-2013$ & 94 & 465 & $0.106 \%$ & 4 \\
$2008-2016$ & 236 & 3157 & $0.113 \%$ & 4 \\
$2008-2019$ & 336 & 6949 & $0.123 \%$ & 4 \\
\hline
\end{tabular}

Fig. 3 The co-word network of 2008-2010

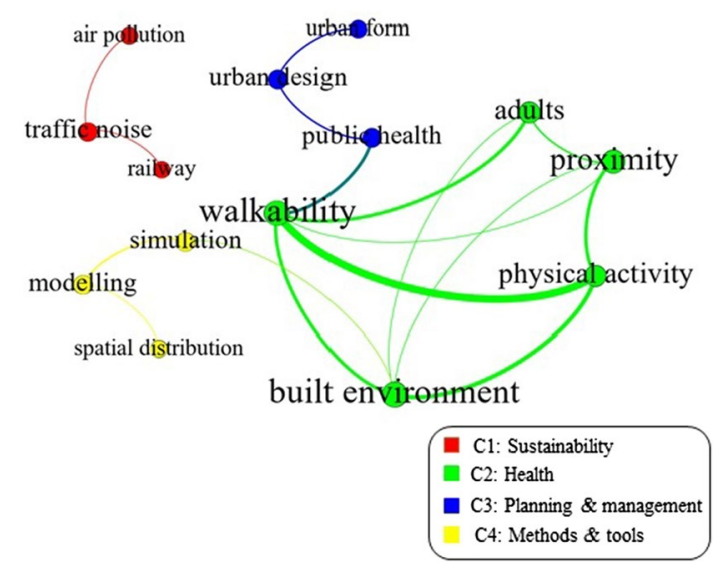

not feasible to show all nodes in each clusters owing to the limitations of two-dimensional visualization.

Network density (D) is the ratio between the actual number of edges and the maximum possible number of edges that can be obtained from the network, which is calculated by the formula in the following:

$$
D=\frac{2 E}{N(N-1)}
$$

where:

$\mathrm{D}=$ density of co-word network

$\mathrm{E}=$ numbers of edges in the network

$\mathrm{N}=$ numbers of nodes in the network

The higher value of density for co-word network infers that research subjects have been well-developed and thus more mature evolution of the knowledge system (Liu et al. 2011; Zhang et al. 2017). The network density of four steps from 2008 to 2019 changed from $0.186 \%$ to $0.106 \%, 0.113 \%$ and finally $0.123 \%$ (see Table 5). Jaccard index is used to normalize the co-occurance links in the network. Regarding the minority of literature for the period between 2008 and 2010, there was a close relationship between the keywords, and consequently greater density. From 2011 to 2013, the number of subjects was rising, but the quantification of publications for each subject was still limited. As a result, the relation between the keywords became more divergent. Since that time to 2019 , both the subject diversity and the publication quantification for each subject was rising gradually until it reached an equilibrium point $0.123 \%$. According to the results 


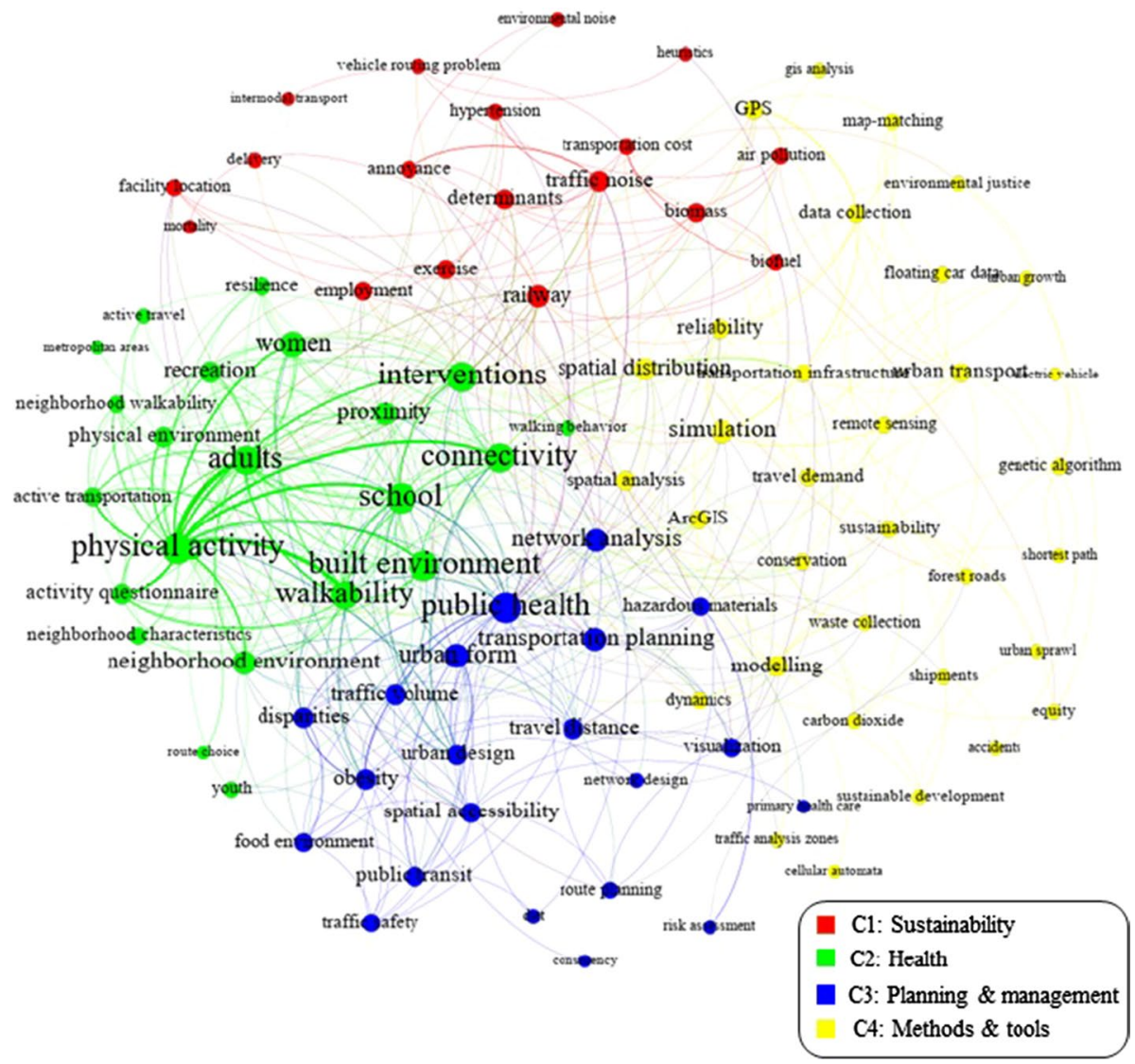

Fig. 4 The co-word network of 2008-2013

of network density equation, it can be concluded that the research into GIS-T is not mature sufficient yet.

\section{Construction of strategic diagram}

Using the information included in the Table 6, we are able to form strategic diagrams for each period. A strategic diagram is used to illustrate the status quo and direction of research themes on GIS-T more vividly. Relying on the clustering results, strategic diagrams enable us to visualize the cohesion and maturity of the research themes in GIS-T, using the centrality and density of each cluster (Callon et al. 1991; Liu et al. 2014a, b; Wanying et al. 2018; Giannakos et al. 2019). The centrality indicates the strength of an interaction between nodes, while density shows the internal coherence of a cluster (Giannakos et al. 2019). In other words, centrality shows how "central" a theme is to the whole field, and the level of internal relationships and connections in a particular research field is illustrated by density (Liu et al. 2011, 2014a, b; Wanying et al. 2018; Giannakos et al. 2019). Strategic diagrams have been utilized in wide range of studies such as iMetrics (Khasseh et al. 2017), social media (Gan and Wang 2015), 


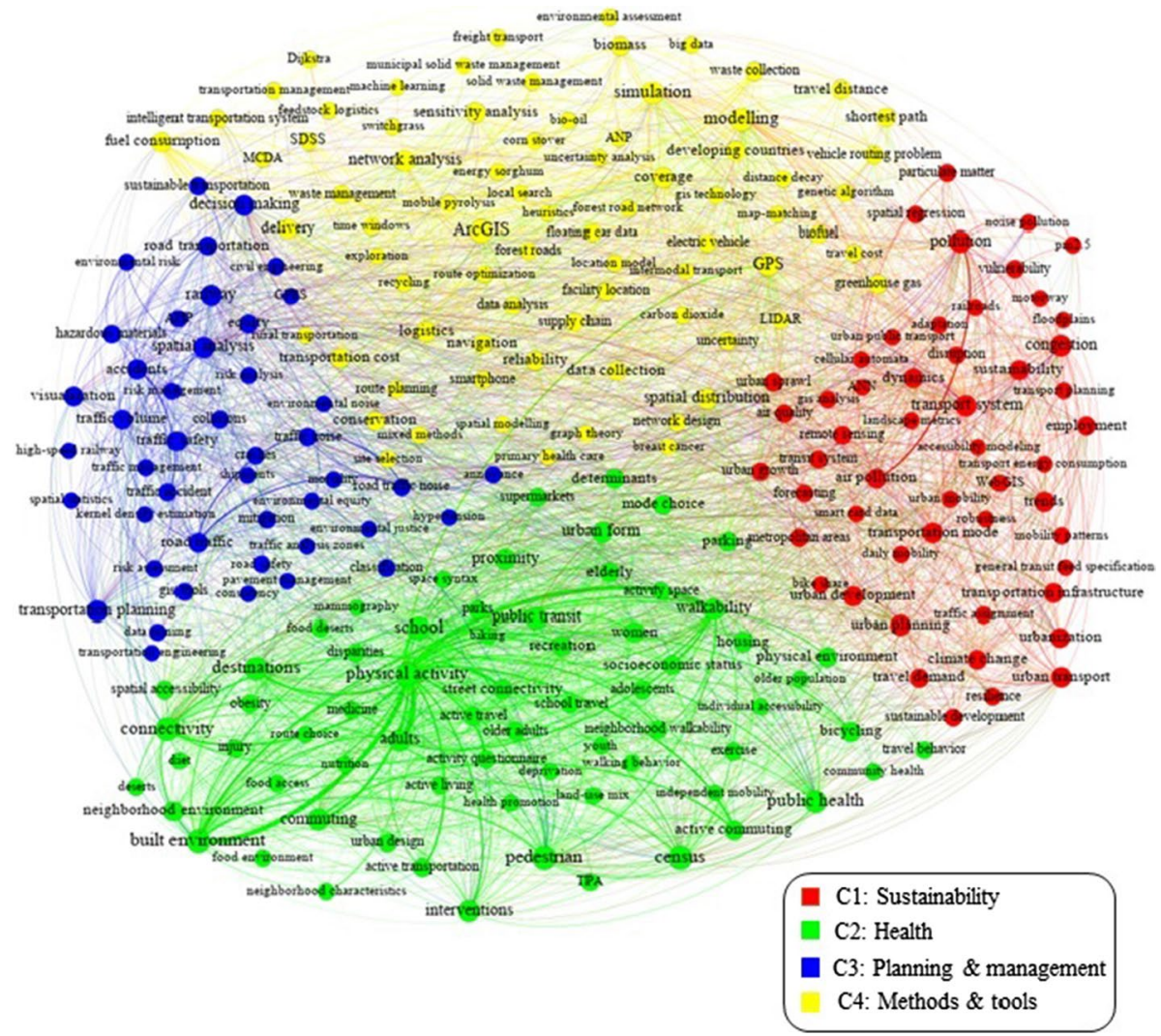

Fig. 5 The co-word network of 2008-2016

computer behavior (Muñoz-Leiva et al. 2012), information science (Zong et al. 2013; $\mathrm{Hu}$ et al. 2013), stem cells (An and Wu 2011), gender differences (Dehdarirad et al. 2014). According to a conducted research by Moral-Muñoz et al. (2020), some science mapping software such as SciMAT, and libraries such Bibliometrix support strategic diagram.

According to Fig. 7, the strategic diagram divides the clusters into four individual quadrants, which x-axis and y-axis are labeled with degree centrality and density respectively (Callon et al. 1991). The level of development and maturity of a specific cluster is defined based on the quadrant it is located, as follows: (a) quadrant I: welldeveloped and mainstream, (b) quadrant II: developed but isolated, (c) quadrant III: emerging or declining, (d) quadrant IV: undeveloped and general (Callon et al. 1991). In order to estimate the origin of each diagram, the average of degree centrality and density for each period is calculated (see Table 7). Based on the clustering results, we plotted the strategic diagram for the years 2008-2019 to visualize the cohesion and maturity of the research themes in GIS-T, using the centrality and density of each cluster (see Fig. 8). 


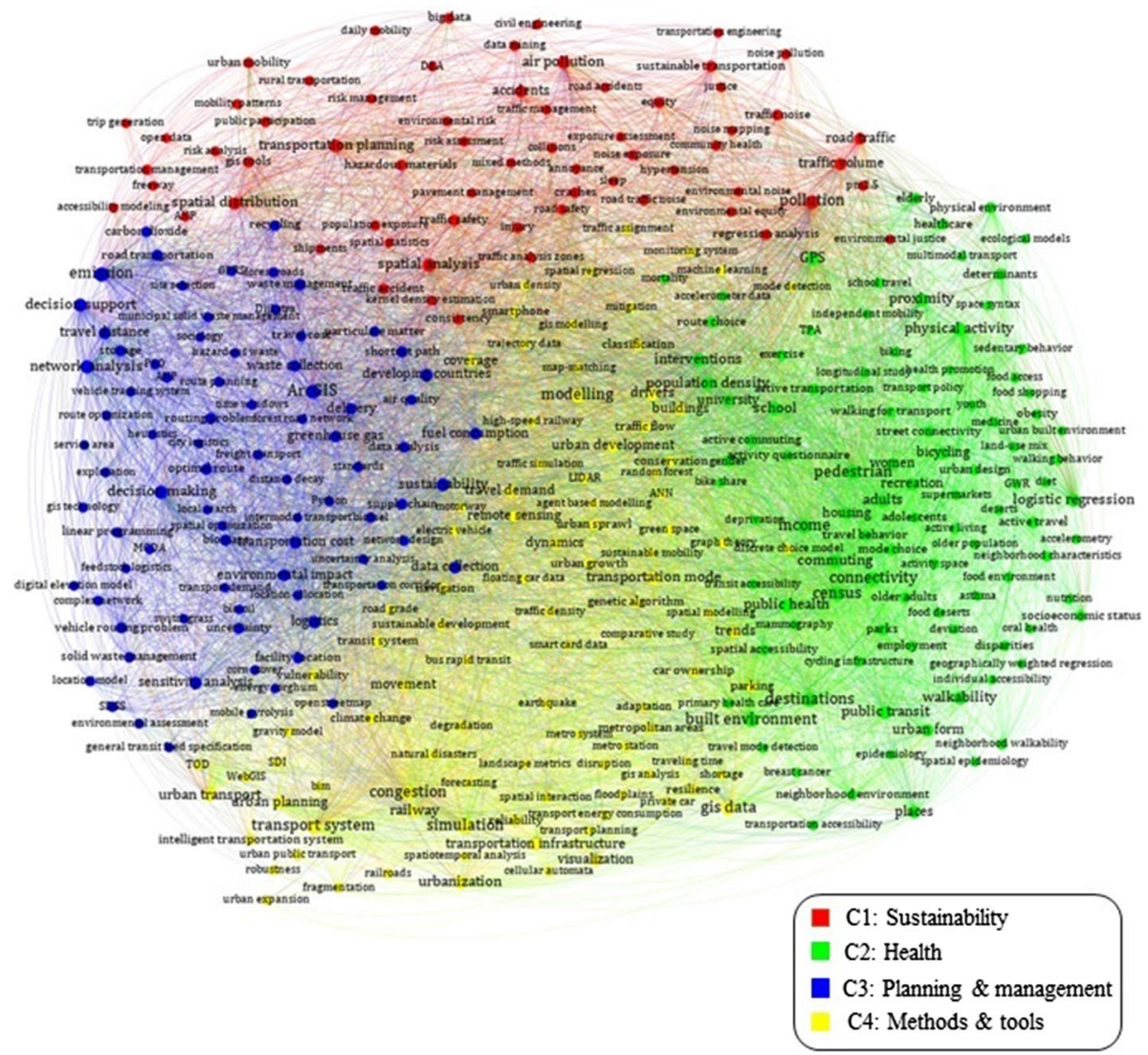

Fig. 6 The co-word network of 2008-2019

\section{Detection of research themes}

To summarize, the main clusters resulted from the co-word analysis for the period 2008-2019 are listed as follows:

\section{- Cluster 1: Sustainability}

This cluster deals with issues related to challenges and opportunities of sustainable transportation in the modern cities. It refers to the broad subject of transportation that in terms of social, environmental and climate impacts is sustainable. It also is seeking to formulate and implement strategies to address the increasing problems (i.e., environmental and health and so on) of living in the metropolitan areas. Most of papers aim to incentivize people to switch from private cars to more sustainable modes of transportation such as walking, cycling and public transit. The hot keywords group included in this subject are "sustainable transportation", "justice", "exposure assessment", "walkability", "mibility patterns", "daily mobility", "equity", "environmental equity", "risk management", "sustainable assessment", "accessibility modelling" etc.

- Cluster 2: Health 


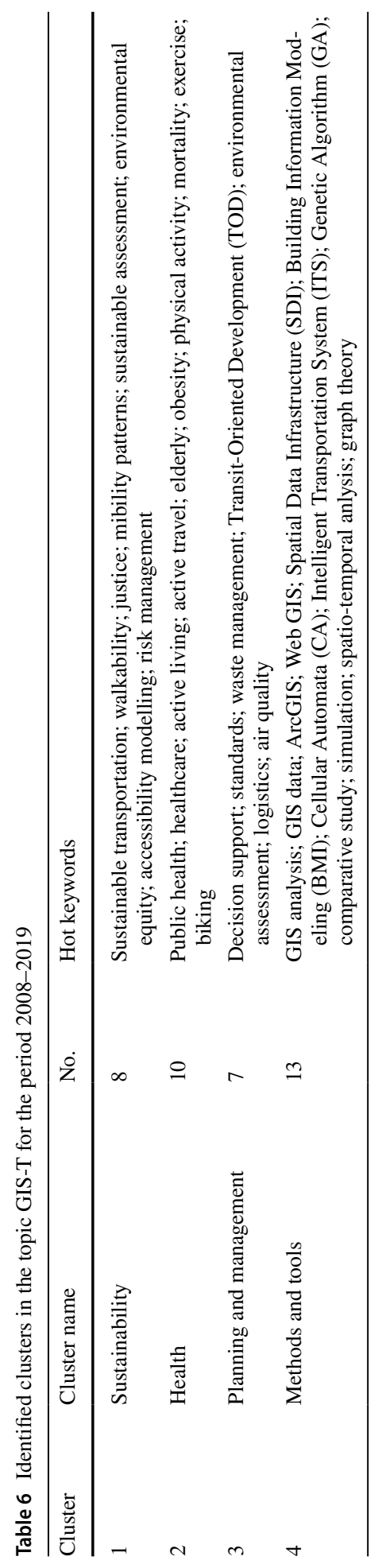




\begin{tabular}{|c|c|}
\hline $\begin{array}{l}\text { Density } \\
\text { Quadrant II: Developed but isolated } \\
\text { themes "Ivory Tower" } \\
\text { The clusters are close to each other, but they are specialized } \\
\text { on one theme. We find specialized field themes here, either } \\
\text { internal themes constituting an autonomous subfield, or } \\
\text { external themes "imported" from other fields or disciplines } \\
\text { and having new development in the studied field. } \\
\qquad \text { Peripheral and Developed }\end{array}$ & $\begin{array}{l}\text { Quadrant I: Motor themes "Mainstream" } \\
\text { Here we find the main themes. Clusters are very close from } \\
\text { each other in term of keywords (high density, strong } \\
\text { association). Furthermore, as centrality is high, these } \\
\text { themes are linked to several others. } \\
\text { Central and Developed }\end{array}$ \\
\hline $\begin{array}{l}\text { Quadrant III: Emerging or declining themes } \\
\text { "Chaos/Unstructured" } \\
\text { These themes may evolve to the right, gaining centrality, and } \\
\text { evolve upwards, gaining density. They might be at the origin } \\
\text { of new trends or development within the field. }\end{array}$ & $\begin{array}{l}\text { Centrality } \\
\text { Quadrant IV: Basic and transversal themes } \\
\text { "Bandwagon" } \\
\text { Clusters are linked by numerous keywords (high centrality) } \\
\text { but are very different from each other (low density). Here we } \\
\text { find promising or past themes that are part of the discipline } \\
\text { or themes borrowed from other disciplines/context themes. } \\
\text { This quadrant is important as the themes are essential for a } \\
\text { good understanding of the field. } \\
\text { Central and Undeveloped }\end{array}$ \\
\hline
\end{tabular}

Fig. 7 Density and centrality in a strategic diagram (Giannakos et al. 2019)

Table 7 Degree centrality and density of clusters in the co-word analysis

\begin{tabular}{|c|c|c|c|c|c|c|c|c|}
\hline \multirow{2}{*}{$\begin{array}{l}\text { Periods } \\
\text { Clusters }\end{array}$} & \multicolumn{2}{|c|}{$2008-2010$} & \multicolumn{2}{|c|}{$2008-2013$} & \multicolumn{2}{|c|}{$2008-2016$} & \multicolumn{2}{|c|}{ 2008-2019 } \\
\hline & $D C$ & $D$ & $D C$ & $D$ & $D C$ & $D$ & $D C$ & $D$ \\
\hline 1: Sustainability & 4 & 0.16 & 145 & 0.30 & 978 & 0.20 & 2041 & 0.18 \\
\hline 2: Health & 5 & 0.13 & 153 & 0.51 & 1124 & 0.34 & 2773 & 0.29 \\
\hline 3: Planning and management & 0 & 0.16 & 86 & 0.21 & 743 & 0.21 & 2225 & 0.23 \\
\hline 4: Methods and tools & 1 & 0.16 & 82 & 0.13 & 1025 & 0.16 & 3083 & 0.20 \\
\hline
\end{tabular}

$D C$ degree centrality; $D$ density

The main objective of publications included in this cluster is improving people's health and decreased health care costs of transportation activities. Moreover, they commonly offer solutions that supports physical activity such as investments in sidewalks, trails, public transit, bike lanes, and other infrastructure. This cluster to the some extent has some similar aspects and objectives to the cluster 1 . The hot keywords of this topic consist of "elderly", "healthcare", "obesity", "physical activity", "active commuting", "noise exposure", "walking behaviour", "mortality", "exercise", "active travel”, "active living", "ecological models", "bicycling", "biking", "public health", "breast cancer" etc.

- Cluster 3: Planning and Management

This cluster is made up of subjects focusing on defining future goals, policies, and investments to prepare for future needs to efficiently move people and goods to destinations. Studies in this cluster commonly are seeking to find and use practical solutions to improve the performance of urban transportation. They provide comprehensive 


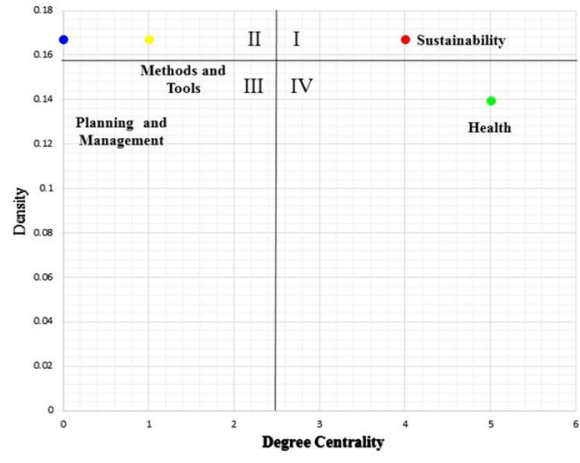

2008-2010

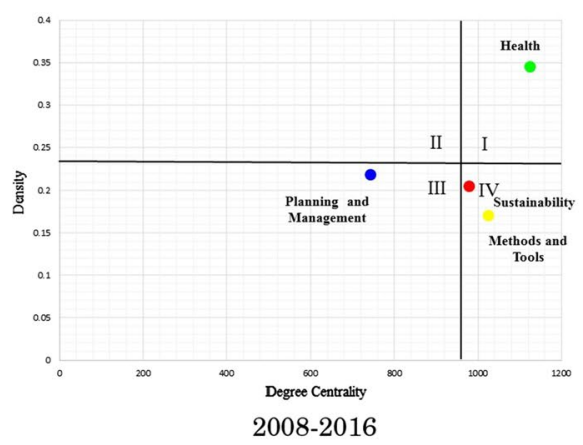

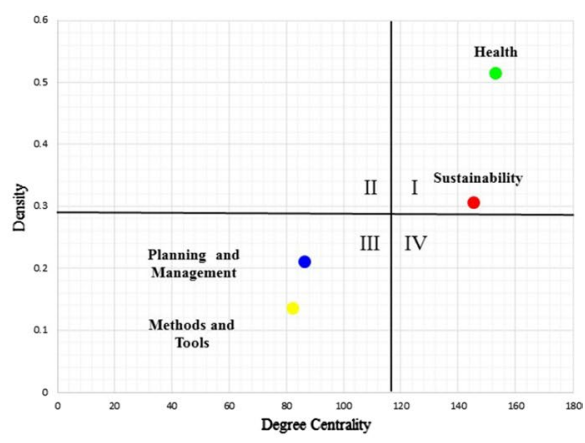

2008-2013

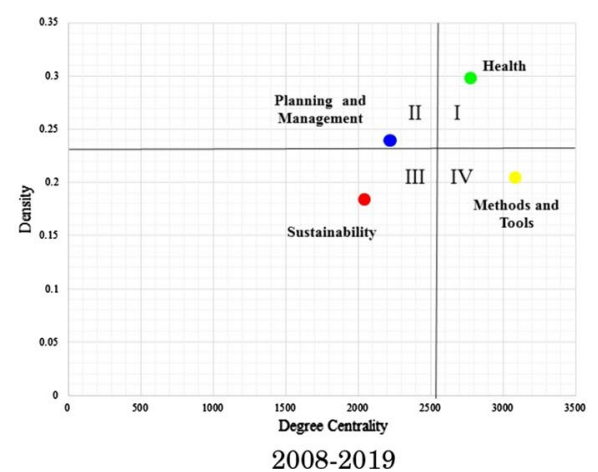

Fig. 8 The strategic diagram of clusters for the periods between 2008 and 2019

approaches to analyze a wide range of alternatives and impacts on the transportation system to influence beneficial outcomes. The highly significant keywords in this topic includes "decision support", "standards", "travel cost", "transportation cost", "location model", "municipal solid waste management", "inter-model transportation", "logistics", "environmental assessment", Transit-Oriented Development (TOD), "facility creation", "waste management", "recycling", "air quality" etc.

- Cluster 4: Methods and Tools

The co-word analysis discovered a number of heterogeneous methods and tools that are commonly utilized in the literature. This cluster is connected to the terms such as "GIS analysis", "GIS data", "ArcGIS", "Web GIS", "Spatial Data Infrastructure (SDI)", "Building Information Modeling (BMI)", "Cellular Automata (CA)", "Agent-Based Modelling (ABM)", "graph theory", comparative study", "Intelligent Transportation System (ITS)", "Genetic Algorithm (GA)", "data collection”, "simulation”, "spatiotemporal anlysis" etc.

\section{Dynamic analysis based on two-dimensional map and strategic diagram}

The findings of this paper illuminated that GIS-T topic has an interdisciplinary knowledge system, involving GIS, transportation, computer science, geography, health science, economy, information science, environment, natural resources, and so on. The results of 
the dynamic co-word network and strategic digrams could provide lots of useful information and implications for researchers seeking to predict its future. Based upon our findings, some of significant points are stated in the following:

In the period between 2008 and 2010, the quantification of literature was limited and sparse, thus there were weak links among nodes in different clusters of network. According to the strategic diagrams (see Fig. 8), density and degree centrality for cluster 1 ("Sustainability") were both high. It indicates that this cluster has high internal correlation, and subjects are widely linked with other clusters. The paper published this period, mostly favoured the environmentally sustainable development of transportation infrastructure taking into account urban design, urban expansion, land-use etc. For example, some studies aimed to improve accessibility to green spaces, public transportation, health services etc. by making minimal changes in land-use and transportation network design. The clusters 3 ("Planning and Management") and 4 ("Methods and Tools") located in the quadrant II, which means that these research topics were well-developed but not central. Some studies concentrated on developing and using new methods and tools that can assist urban planners in management of urban transportation system. We found many papers that applied evolutionary algorithms to find the shortest or best route in travelling salesman problem or vehicle routing problem (e.g., genetic algorithm, ant colony optimization etc.). Many studies used ArcGIS software for presenting spatial data in the format of schematic maps (i.e., service areas of public transportation, traffic maps etc.). Cluster 2 ("Health") positioned in the quadrant IV with high degree centrality but low density. A few studies made efforts to appraise the urban transportation system with regard to public health and sustainability aspects. All in all, in spite of detection of 4 clusters for this era, the research works were inconsistent, thus the network is immature and undeveloped (Table 7).

Since 2011, was a turning point as we witnessed two significant changes in literature on GIS-T. First, a marked increase in the volume of academic research works in GIS-T led to the complexity and burgeoning of the network. It means that the knowledge network became richer, so the border of communities was more distinctive. Furthermore, the position of Cluster 2 ("Health") promoted from quadrant IV to I, inferring the increasing attention of researchers to do reaseach into health topic in this period. In this period, the cluster 2 ("Sustainability") still located in the quadrant I, showing the considerable significance of sustainable transportation in the global scale. The academic works published in the area of "Planning and Management" and "Methods and Tools" were sparse and negligible for this period, thus these clusters located in the quadrant III, indicating the marginality and immaturity of this research topic. In this period, some studies tried to employ simulation approaches for transportation applications, for instance, simulation of travel mode of commuters using agent-based modeling, prediction of urbanization in cities by cellular automata, etc. There were many papers which favoured the logistics transportation and distribution topic, which encompass a wide range of applications from the collection of municipal waste and hazardous materials, to distribution of factories and suppliers' products among consumers in the urban areas (Fig. 9).

In the period 2008 to 2016, the cluster 2 ("Health") still located in the quadrant I, due to increasing improvement in quantification and qualification of scientific research in public health concept. A part of studies introduced the irreversible negative consequences of transportation activities on people health and urban environment, which were carried out by scholars from medical science community. The hot research topics were comprised of physical activity, sedentary lifestyle, obesity, air pollution, acid rain, climate change, respiratory diseases etc. It can be seen that the clusters 1 ("Sustainability") and 4 ("Methods and Tools") dropped to quadrant IV, showing high degree centrality but low density. Considering the 


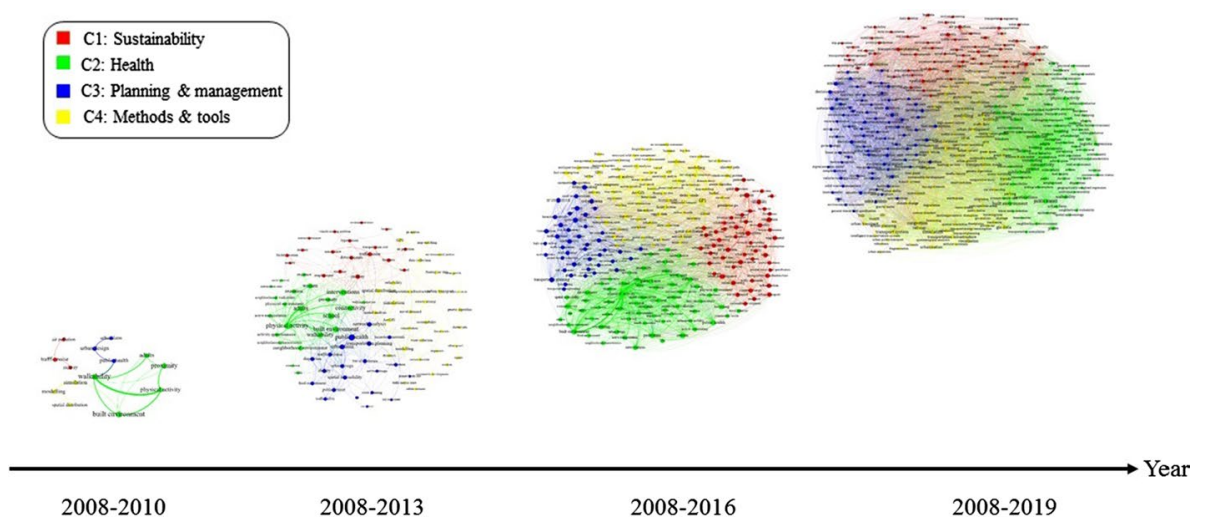

Fig. 9 The dynamic network structure of keywords for years 2008-2019

increase of the spatial data used in transportation applications, we face the difficult task of storage and manipulation of a massive volume of data. Therefore, some studies used ArcSDE software to benefit from Relational Database Management Systems (RDBMS) capabilities for storing and manipulating spatial data related to transportation (i.e., socioeconomics, traffic census etc.). Advancements in information and communication technologies, especially in the Internet led to new capabilities of GIS in the field of transportation such as real-time and interactive traffic maps, mobile GIS etc. Many papers offered new methods and tools to improve the results of previous works in route optimization, collection of hazardous materials, logistics, supply chain, and many more. Also, the cluster 3 ("Planning and Management") located in the quadrant III. A big portion of papers, made considerable efforts to appraise the urban transportation system with regard to numerous aspects such as equitable cities, the future of mobility, inter-connected cities, intelligent transportation, sustainable transportation and so on.

From 2016, considering the strategic diagram, cluster 2 ("Health") with high density and degree centrality still located in the quadrant I, which indicates that the research topics in this cluster tends to be more and more well-developed. Cluster 1 ("Sustainability") placed in quadrant III with low density and degree centrality, indicating the research topics in this cluster is emerging or declining. Clusters 3 ("Planning and Management") and 4 ("Methods and Tools") are positioned in quadrant II, and IV respectively. Similar to the previous period, many studies worked on using new abilities and capabilities of technologies to improve services of transportation network. New research topics mostly directed towards utilizing new concepts such as Internet of Things (IoT), Deep Learning etc. to open up new opportunities and perspectives on intelligent transportation systems in cities. Emergence of new ideas and applications in transportation planning (i.e., demand-driven transportation, autonomous vehicles etc.) is a clear evidence of revolution in the methods and tools used by scholars in addressing transportation problems. 


\section{Conclusions, limitations and future research}

On the basis of publications included in the Web of Science (WoS) database service, and also utilizing co-word analysis, this study mapped the relationships among research topics of GIS-T field. Furthermore, strategic diagrams are used to show the structure and evolution of communities more clearly. In this study, research scope includes the GIS-T publications available in WoS. The results show that the research interest in GIS-T is rather young, and the subjects studied in this area consist of an interdisciplinary and heterogeneous variety of knowledge areas. This study represented a network map of the main themes grouped in four communities including (a) "Sustainability", (b) "Health", (c) "Planning and Management", and (d) "Methods and Tools". For the period from 2008 to 2010, the literature of GIS-T was limited and scattered, with weak edges among nodes in all clusters, but "Sustainability" cluster. Also, the clusters "Planning and Management" and "Methods and Tools" have high internal correlation, with high density and degree centrality. From 2011 onwards, the network is becoming richer and more complex, and it can be seen that the boundaries between clusters seem more clear. The big characteristic of the period 2011-2013 is the displacement of "Health" cluster from IV to I in the strategic diagram, indicating the increasing research works done in health subject. According to knowledge network and strategic diagram, the health issues have been received a considerable after 2010. The researcher mostly have been exploring the positive consequences of active transportation, and investigating the possible solutions for convincing people to avoid driving. In addition, other GIS-T topics keep expanding almost in constant speed. Many researchers made efforts to evaluate the urban transportation system with regard to public health aspects. GIS software and methods have been used to store, manage, analyze and present the pollution data in the urban areas. Also, there are lots of research using optimization approaches for different GIS-T problems, such as route finding, logistics and supply chain management, and so on. From 2008 to 2017 onwards, according to strategic diagram, clusters 2 ("Health") still located positioned in the quadrant I, referring the maturity of these subjects. Day by day, GIS-T filed is experiencing novel concepts and advanced technologies, such as Internet of Things (IoT), Artificial Intelligence (AI) etc. which can open up new opportunities for addressing transportation problems. The future studies can use other databases (i.e., Google Scholar, Scopus etc.) to enrich their dataset. In addition, in order to describe the intellectual structure of the GIS-T field, the next studies can consider complementary bibliometric techniques (i.e., co-citation analysis, co-author analysis etc.). Overall, this study provide researchers with a practical and powerful tool for grasping the current status of GIS-T field, and also better understanding of its evolution. Moreover, as this study was the first attempt to apply text analysis and visualization methods to identification of research subjects of GIS-T, it can be introduced as a roadmap for other applications.

Funding Open Access funding provided by Royal Institute of Technology.

Open Access This article is licensed under a Creative Commons Attribution 4.0 International License, which permits use, sharing, adaptation, distribution and reproduction in any medium or format, as long as you give appropriate credit to the original author(s) and the source, provide a link to the Creative Commons licence, and indicate if changes were made. The images or other third party material in this article are included in the article's Creative Commons licence, unless indicated otherwise in a credit line to the material. If material is not included in the article's Creative Commons licence and your intended use is not permitted by statutory regulation or exceeds the permitted use, you will need to obtain permission directly from the copyright holder. To view a copy of this licence, visit http://creativecommons.org/licenses/by/4.0/. 


\section{References}

An, X. Y., \& Wu, Q. Q. (2011). Co-word analysis of the trends in stem cells field based on subject heading weighting. Scientometrics, 88(1), 133-144.

Aria, M., \& Cuccurullo, C. (2017). Bibliometrix: An R-tool for comprehensive science mapping analysis. Journal of Informetrics, 11, 959-975.

Bastian, M., Heymann, S., \& Jacomy, M. (2009). Gephi: An open source software for exploring and manipulating networks. In International AAAI conference on weblogs and social Media (ICWSM).

Baziyad, H., Shirazi, S., Hosseini, S., \& Norouzi, R. (2020). Mapping the intellectual structure of epidemiology with use of co-word analysis. Journal of Biostatistics and Epidemiology, 5(3), 210-215.

Callon, M., Courtial, J. P., \& Laville, F. (1991). Co-word analysis as a tool for describing the network of interactions between basic and technological research: The case of polymer chemistry. Scientometrics, 22(1), 155-205.

Callon, M., Courtial, J., Turner, W. A., \& Bauin, S. (1983). From translations to problematic networks: An introduction to co-word analysis. Social Science Information, 22(2), 191-235.

Cambrosio, A., Limoges, C., Courtial, J. P., \& Laville, F. (1993). Historical scientometircs? Mapping over 70 years of biological safety research with co-word analysis. Scientometrics, 27(2), 119-143.

Chen, C. (2006). CiteSpace II: Detecting and visualizing emerging trends and transient patterns in scientific literature. Journal of the American Society for Information Science and Technology, 57(3), 359-377.

Cobo, M. J., López-Herrera, A., Herrera-Viedma, E., \& Herrera, F. (2012). SciMAT: A new science mapping analysis software tool. Journal of the Association for Information Science and Technology, 63, 1609-1630.

Corrales-Garay, D., Ortiz-de-Urbina-Criado, M., \& Mora-Valentín, E.-M. (2019). Knowledge areas, themes and future research on open data: A co-word analysis. Government Information Quarterly, 36(1), 77-87.

Coulter, N., Monarch, I., \& Konda, S. (1998). Software engineering as seen through its research literature: A study in co-word analysis. American Society for Information Science, 49(13), 1206-1223.

Dehdarirad, T., Villarroya, A., \& Barrios, M. (2014). Research trends in gender differences in higher education and science: A co-word analysis. Scientometrics, 101(1), 273-290.

Eck, N. J., \& Waltman, L. (2009). Software survey: VOSviewer, a computer program for bibliometric mapping. Scientometrics, 84, 523-538.

Feng, Y., Zhu, Q., \& Lai, K. H. (2017). Corporate social responsibility for supply chain management: A literature review and bibliometric analysis. Journal of Cleaner Production, 158, 296-307.

Fletcher, D.R. (2000). Geographic information systems for transportation: A look forward. Washington, DC: Committee on Spatial Data and Information Science (A5015), US Transportation Research Board.

Gan, C., \& Wang, W. (2015). Research characteristics and status on social media in China: A bibliometric and co-word analysis. Scientometrics, 105(2), 1167-1182.

Giannakos, M., Papamitsiou, Z., Markopoulos, P., Read, J., \& Hourcade, J. P. (2019). Mapping child-computer interaction research through co-word analysis. International Journal of Child-Computer Interaction, 100165, 23-24.

Goodchild, M. F. (1992). Geographic information science. Geographic Information Systems, 6(1), 31-45.

Goodchild, M. F. (2000). GIS and transportation: Status and challenges. GeoInformatica, 4(2), 127-139.

Hoz-Correa, A., Muñoz-Leiva, F., \& Bakucz, M. (2018). Past themes and future trends in medical tourism research: A co-word analysis. Tourism Management, 65, 200-211.

Hu, C. P., Hu, J. M., Deng, S. L., \& Liu, Y. (2013). A co-word analysis of library and information science in China. Scientometrics, 97(2), 369-382.

Igami, M. P. Z., Bressiani, J. C., \& Mugnaini, R. (2014). A new model to identify the productivity of theses in terms of articles using co-word analysis. Scientometric Research, 3(1), 3.

Khasseh, A. A., Soheili, F., Sharif Moghaddam, H., \& Mousavi Chelak, A. (2017). Intellectual structure of knowledge in iMetrics: A co-word analysis. Information Processing \& Management, 53(3), 705-720.

Lewis, S. (1990). Use of geographical information systems in transportation modeling. ITE Journal, 60(3), 34-38.

Leydesdorff, L., \& Vaughan, L. (2006). Co-occurrence matrices and their applications in information science: Extending ACA to the web environment. Journal of the American Society for Information Science and technology, 57(12), 1616-1628.

Li, T., Bai, J., Yang, X., Liu, Q., \& Chen, Y. (2018). Co-occurrence network of high-frequency words in the bioinformatics literature: Structural characteristics and evolution. Applied Sciences, 8(10), 1994.

Lin, S. M., McConnell, P., \& Johnson, K. F. (2004). MedlineR: An open source library in R for medline literature data mining. Bioinformatics, 20(8), 3659-3661. 
Liu, G.-Y., Hu, J.-M., \& Wang, H.-L. (2011). A co-word analysis of digital library field in China. Scientometrics, 91(1), 203-217.

Liu, Y., Goncalves, J., Ferreira, D., Xiao, B., Hosio, S., \& Kostakos, V. (2014a). CHI 1994-2013: Mapping two decades of intellectual progress through co-word analysis. In Proceedings of the SIGCHI conference on human factors in computing systems., pp. 3553-3562.

Liu, Y., Goncalves, J., Ferreira, D., Hosio, S., \& Kostakos, V. (2014b). Identity crisis of ubicomp?: Mapping 15 years of the field's development and paradigm change, In Proceedings of the 2014 ACM International joint conference on pervasive and ubiquitous computing, ACM, 2014, pp. 75-86.

Newman, M. E. J. (2004). Fast algorithm for detecting community structure in networks. Physical Review E, 69, 066-133.

Miller, H., \& Shaw, S.-L. (2001). Geographic information systems for transportation: Principles and applications. New York: Oxford University Press.

Moral-Muñoz, J. A., Herrera-Viedma, E., Santisteban-Espejo, A., \& Cobo, M. J. (2020). Software tools for conducting bibliometric analysis in science: An up-to-date review. El professional de la informacion, 29(1), e290103.

Muñoz-Leiva, F., Viedma-del-Jesús, M. I., Sánchez-Fernández, J., \& López-Herrera, A. G. (2012). An application of co-word analysis and bibliometric maps for detecting the most highlighting themes in the consumer behaviour research from a longitudinal perspective. Quality \& Quantity, 46(4), 1077-1095.

Nguyen, D. (2019). Mapping knowledge domains of non-biomedical modalities: A large-scale co-word analysis of literature 1987-2017. Social Science \& Medicine, 233, 1-12.

Noyons, E. C. M., \& van Raan, A. F. J. (1998). Monitoring scientific developments from a dynamic perspective: Self-organized structuring to map neural network research. Society for Information Science, 49(1), 68-81.

Olmeda-Gómez, C., Ovalle-Perandones, M.-A., \& Perianes-Rodríguez, A. (2017). Co-word analysis and thematic landscapes in Spanish information science literature, 1985-2014. Scientometrics, 113(1), 195-217.

Peters, H. P., \& Van Raan, A. F. (1993). Co-word-based science maps of chemical engineering. Part I: Representations by direct multidimensional scaling. Research Policy, 22(1), 23-45.

Pritchard, A. (1969). Statistical bibliography or bibliometrics. Journal of Documentation, 25(4), 348-349.

Ravikumar, S., Agrahari, A., \& Singh, S. N. (2015). Mapping the intellectual structure of scientometrics: A co-word analysis of the journal Scientometrics (2005-2010). Scientometrics, 102(1), 929-955.

Rashidi, K., Noorizadeh, A., Kannan, D. \& Cullinane, K. (2020). Applying the triple bottom line in sustainable supplier selection: A meta-review of the state-of-the-art. Journal of Cleaner Production, 122001.

Shaw, S.-L. (2010). Geographic information systems for transportation: From a static past to a dynamic future. Annals of GIS, 16(3), 129-140.

Shiau, W.-L., Dwivedi, Y.-K., \& Tsai, C.-H. (2015). Supply chain management: Exploring the intellectual structure. Scientometrics, 105(1), 215-230.

Simkowitz, H. J. (1988). Transportation applications of geographic information systems. Computers, Environment and Urban Systems, 12, 253-71.

Thill, J.-C. (2000). Geographic information systems for transportation in perspective. Transportation Research $C, 8(1-6), 3-12$.

Van Eck, N.J., \& Waltman, L., (2014). Visualizing bibliometric networks. In: Measuring scholarly impact. Springer, Berlin. pp. 285-320.

Viedma-Del-Jesús, M. I., Perakakis, P., Munoz, M. A., Lopez-Herrera, A. G., \& Vila, J. (2011). Sketching the first 45 years of the journal psychophysiology (1964-2008): A co-word-based analysis. Psychophysiology, 48(8), 1029-1036.

Wang, H., Pan, Y., \& Luo, X. (2019). Integration of BIM and GIS in sustainable built environment: A review and bibliometric analysis. Automation in Construction, 103, 41-52.

Wang, Z., Zhao, H., \& Wang, Y. (2015). Social networks in marketing research 2001-2014: A co-word analysis. Scientometrics, 105(1), 65-82.

Wanying, Z., Jin, M., \& Kun, L. (2018). Ranking themes on co-word networks: Exploring the relationships among different metrics. Information Processing \& Management, 54(2), 203-218.

Waters, N. (1999). Transportation GIS: GIS-T. In P. Longley, M. Goodchild, D. Maquire, \& D. Rhind (Eds.), Geographical information systems: Principles, techniques, management and applications (pp. 827-844). New York: Wiley.

Wu, D., Song, Y., Xie, K., \& Zhang, B. (2018). Traits and causes of environmental loss-related chemical accidents in China based on co-word analysis. Environmental Science and Pollution Research, 25(18), 18189-18199. 
Xie, P. (2015). Study of international anticancer research trends via co-word and document co-citation visualization analysis. Scientometrics, 105(1), 611-622.

Xie, J., \& Szymanski, B. (2011). Community detection using a neighborhood strength driven label propagation algorithm. In Proceedings of the 2011 IEEE 1st international network science workshop, NSW 2011.

Yan, B.-N., Lee, T.-S., \& Lee, T.-P. (2015). Mapping the intellectual structure of the Internet of Things (IoT) field (2000-2014): A co-word analysis. Scientometrics, 105(2), 1285-1300.

Yang, Y., Wu, M., \& Cui, L. (2012). Integration of three visualization methods based on co-word analysis. Scientometrics, 90(2), 659-673.

Yue, H. (2012). Mapping the intellectual structure by co-word: A case of international management science. International Conference on web information systems and mining (pp. 621-628). Berlin, Heidelberg: Springer.

Zhang, Q.-R., Li, Y., Liu, J.-S., Chen, Y.-D., \& Chai, L.-H. (2017). A dynamic co-word network-related approach on the evolution of China's urbanization research. Scientometrics, 111(3), 1623-1642.

Zong, Q. J., Shen, H. Z., Yuan, Q. J., Hu, X. W., Hou, Z. P., \& Deng, S. G. (2013). Doctoral dissertations of Library and Information Science in China: A co-word analysis. Scientometrics, 94(2), 781-799.

\section{Affiliations}

\section{Seyedmohammadreza Hosseini ${ }^{1}$ (D) - Hamed Baziyad ${ }^{2} \cdot$ Rasoul Norouzi $^{2}$. Sheida Jabbedari Khiabani ${ }^{2} \cdot$ Győző Gidófalvi $^{3}$. Amir Albadvi $^{2}$. Abbas Alimohammadi $^{4}$. Seyedehsan Seyedabrishami ${ }^{5}$}

Hamed Baziyad

hamed_baziyad@modares.ac.ir

Rasoul Norouzi

rasoulnorouzi@modares.ac.ir

Sheida Jabbedari Khiabani

j.sheida@modares.ac.ir

Győző Gidófalvi

gyozo.gidofalvi@abe.kth.se

Amir Albadvi

albadvi@modares.ac.ir

Abbas Alimohammadi

alimoh_abb@kntu.ac.ir

Seyedehsan Seyedabrishami

seyedabrishami@modares.ac.ir

1 Department of Earth and Space Science and Engineering, Lassonde School of Engineering, York University, 4700 Keele St., Toronto, ON M3J 1P3, Canada

2 Department of Information Technology, Faculty of Industrial and Systems Engineering, Tarbiat Modares University, Tehran, Iran

3 Division of Geoinformatics, Department of Urban Planning and Environment, KTH Royal Institute of Technology, Stockholm, Sweden

4 Department of Geospatial Information Systems, Faculty of Geodesy and Geomatics Engineering, K. N. Toosi University of Technology, Tehran, Iran

5 Department of Civil and Environmental Engineering, Tarbiat Modares University, Tehran, Iran 